\title{
Evaluation of Liver Function and the Role of Biliary Drainage before Major Hepatic Resections
}

\author{
Yuzo Yamamoto \\ Department of Gastroenterological Surgery, Akita University Graduate School of Medicine, Akita, Japan
}

\section{Keywords}

Future liver remnant - Liver function test - Volumetry . Heterogeneity · SPECT

\begin{abstract}
Background: Prevention of posthepatectomy liver failure is a prerequisite for improving the postoperative outcome of perihilar cholangiocarcinoma. From this perspective, appropriate assessment of future liver remnant (FLR) function and the optimized preparation are mandatory. Summary: FLR volume ratio using $\mathrm{CT}$ volumetry based on 3-dimensional vascular imaging is the current assessment yardstick and is sufficient for assessing a normal liver. However, in a liver with underling parenchymal disease such as fibrosis or prolonged jaundice, weighing up the degree of liver damage against the FLR volume ratio is necessary to know the real FLR function. For this purpose, the indocyanine green (ICG) clearance test, monoethylglycinexylidide (MEGX) test, liver maximum capacity (LiMAX) test, ${ }^{99 \mathrm{~m}}$ Tc-labeled galactosyl human serum albumin ( ${ }^{99 m}$ Tc-GSA) scintigraphy, albumin-bilirubin $(A L B I)$ grade, and ALPlat (albumin $\times$ platelets) criterion are used. After the optimization of FLR function by means of portal vein embolization or associating liver partition and PVL (portal vein ligation) for staged hepatectomy (ALPPS), SPECT scintigraphy with either ${ }^{99 \mathrm{~m} T c-G S A}$ or ${ }^{99 \mathrm{~m} T c-m e b r o f e n i n}$ compensates for misestimation due to the regional heterogeneity of liver function. The role of preoperative biliary drainage has long been debated, with the associated complications having led to a lack of approval. However, the re-
\end{abstract}

cent establishment of safety and an improvement in success rates of endoscopic biliary drainage seem to be changing the awareness of the importance of biliary drainage. Key Messages: Appropriate selection of an assessment method is of prime importance to predict the FLR function according to the preoperative condition of the liver. Preoperative biliary drainage in patients with perihilar cholangiocarcinoma is gaining support due to the increasing safety and success rate, especially in patients who need optimization of their liver function before hepatectomy.

(c) 2020 S. Karger AG, Basel

\section{Introduction}

The outcome of hepatectomy has improved dramatically in recent decades owing to a combination of the refinement of surgical techniques and the careful assessment of patients' tolerance to liver failure. Posthepatectomy mortality still occurs in the range of $3.9-7.6 \%$ in the USA. In the case of perihilar cholangiocarcinoma, the 90 -day mortality rate is $12 \%$ in Western countries [1]. According to a nationwide survey in Japan, 90-day operative mortality after hepatectomy for hilar bile duct cancer has been reported as $7.0 \%$, while overall mortality after hepatectomies is $4.0 \%$ [2]. Several surgical factors are associated with this mortality rate, including abscess formation due to bile leakage and complications after revascularization, but posthepatectomy liver failure (PHLF) occurs in $9-40 \%$ of cases depending on the 
severity of the underlying liver disease [3]. Therefore, assessment of the future liver remnant (FLR) function is of prime importance for major hepatectomy to decrease the risk of PHLF.

Alongside the volume of the liver remnant, the existence of jaundice with or without infection is another important risk factor for PHLF. Belghiti et al. [4] reported extremely high mortality (21\%) in patients with jaundice in comparison to those with normal liver in their analysis of 747 hepatectomies. The necessity of biliary drainage before hepatectomy is still under debate.

This article summarizes the current overview of the evaluation of liver function before major hepatectomy in perihilar cholangiocarcinoma, and the role of biliary drainage in patients with obstructive jaundice, focusing particularly on differences in approach between Western countries and Japan.

\section{Evaluation of the Volume of the FLR}

The FLR function is nowadays primarily determined by CT volumetry as FLR volume ratio or FLR\% (volume of FLR/total liver volume before hepatectomy) [5]. There are 2 concepts. The first is the ratio of FLR volume to the standardized liver volume matching the size of the body. This concept is used to guarantee the posthepatectomy minimum requirement of the liver volume commensurate with body size. The standardized liver volume is usually calculated from body surface area, applying the equation devised by Vauthey et al. [6]. For this method, only the FLR volumetry is required but the volumetry of the total liver is not necessary. The other concept is the ratio of FLR volume to the total liver volume before liver resection in each individual. This method has an advantage, in that a virtual value such as standardized liver volume is not necessary, but requires exclusion of the tumor volume (especially when it is significantly large enough to affect the FLR\%, although this is seldom the case in perihilar cholangiocarcinoma) to calculate the total liver volume because the tumor lesions are not the functional part [7]. Previously, it was difficult to exclude the tumor volume, especially when there were multiple tumors, but recent advances in the volumetry program of the image analyzer have resolved this $[8-10]$.

It is generally accepted that both methods have benefits, and both are in use around the world depending on user preference. The second might be advantageous when considering the incorporation of the regional heterogeneity of liver function (described below).

\section{Evaluation of the Whole Liver Function with Respect to Background Disease}

FLR volume or FLR\% does not always guarantee the sufficiency of posthepatectomy liver function in patients with underlying liver parenchymal diseases. To compensate for this, the following examinations are often undertaken.

\section{Indocyanine Green Clearance Test}

Indocyanine green (ICG) is a dye that is not metabolized and is excreted actively into the bile juice almost completely without entering the enterohepatic recirculation. The speed of its elimination from the blood reflects the capacity of the liver to uptake and excrete organic anions such as bilirubin. As a parameter of its plasma clearance rate, $\mathrm{ICGR}_{15}$ (the percentage of the residual ICG dye 15 min after injecting it) and the plasma clearance rate constant, $\mathrm{K}_{\mathrm{ICG}}$, have long been used. Due to the wide use of the Makuuchi criteria, i.e., that ICGR $_{15}$ should be $<10 \%$ for a resection of two-thirds of the liver resection or more and $<19 \%$ for a one-third resection [11], $\mathrm{ICGR}_{15}$ is now more prevalent than $\mathrm{K}_{\mathrm{ICG}}$. Although the reliability of the ICG clearance test has been established for liver resection, there are several factors limiting the use of this test. Because ICG is excreted into the bile mechanistically through transporters, i.e., $\mathrm{Na}(+)$ /taurocholate cotransporting polypeptide (NTCP) and organic anion-transporting polypeptide 8 (OATP8) [12], this excretion competes with bilirubin. Therefore, $\mathrm{ICGR}_{15}$ or $\mathrm{K}_{\mathrm{ICG}}$ values measured under the condition of hyperbilirubinemia $>3 \mathrm{mg} / \mathrm{dL}$ ( $50 \mu \mathrm{mol} / \mathrm{L}$ ) are unreliable, and this is often encountered in patients with perihilar cholangiocarcinoma. In such instances, the bilirubin level has to first decrease following biliary drainage. In addition, some patients, albeit it not many, have a constitutional ICG excretory defect.

\section{Monoethylglycinexylidide Test}

The monoethylglycinexylidide (MEGX) test is a dynamic liver function test based on the hepatic conversion of lidocaine to MEGX by the cytochrome P450 system [13]. MEGX values $<25 \mathrm{ng} / \mathrm{mL}$ reportedly predict postoperative complications even if a patient is classified as Child A [14].

\section{Liver Maximum CapacityTest}

The liver maximum capacity (LiMAx) test $\left({ }^{13} \mathrm{C}\right.$-methacetin breath test) also evaluates the activity of the cytochrome $\mathrm{P} 450$ system. The normal range of LiMAx values is $311-575 \mu \mathrm{g} / \mathrm{kg} / \mathrm{h}$, with a maximum of ${ }^{13} \mathrm{CO}_{2}$ excretion 10 \pm 6 min after methacetin injection [15]. Recently, using this test on a patient who was on a ventilator, Makridis and Oldhafer [16] reported the experience of intraoperative real- 
time measurement during liver surgery. Such trials might give new insight for further advanced use of the LiMAx test.

\section{${ }^{99 m}$ Tc-Labeled Galactosyl Human Serum Albumin Scintigraphy}

The asialoglycoprotein receptor (ASGP-R) on the hepatocyte membrane specifically binds with serum ASGP and internalizes the proteins to transfer to lysosomes. The total amount of ASGP-R is thought to be proportional to the number of functioning hepatocytes [17]. ${ }^{99 \mathrm{~m}} \mathrm{Tc}-\mathrm{la}-$ beled galactosyl human serum albumin ( $\left.{ }^{99 \mathrm{~m}} \mathrm{Tc}-\mathrm{GSA}\right)$ is a synthesized analog ligand of ASGP for probing the function and/or amount of ASGP-R in vivo [18]. Its behavior after being injected into the blood thus follows the pharmacokinetics of ASGP.

Liver function is interpreted by means of the most classic parameters, receptor index (LHL15) and clearance in$\operatorname{dex}(\mathrm{HH} 15): \mathrm{LHL}=$ count for the liver at $15 \mathrm{~min} / \mathrm{sum}$ of the counts for the heart and liver at $15 \mathrm{~min} ; \mathrm{HH} 15=$ count for the heart at $15 \mathrm{~min} /$ count for the heart at $3 \mathrm{~min}$ [19]. However, the interpretation of liver function from these parameters is qualitative and can only be classified into 4 categories of liver damage (normal, lightly damaged, moderately damaged, or severely damaged). Variable parameters have also been proposed including GSA index (LHL15/HH15), LU15, GSA-R-max with the 5-compartment model, uptake index, liver uptake ratio (LUR) and liver uptake density (LUD), index of convexity (IOC), etc. However, none of these has been widely adopted in clinical practice because they are not stable enough or are too complex to compute. The great advantage of ${ }^{99 \mathrm{~m}} \mathrm{Tc}-\mathrm{GSA}$ scintigraphy in assessing liver function in a patient with perihilar cholangiocarcinoma is that, unlike ICG, the ${ }_{99 \mathrm{~m} T c-G S A}$ uptake by the liver is not affected by the serum bilirubin concentration.

\section{Other Indices}

The albumin-bilirubin (ALBI) grade has been established as a convenient model to assess hepatic function in patients with hepatocellular carcinoma [20]. Although it has recently been proven that ALBI grade can replace Child-Pugh grade in predicting the posthepatectomy outcome and survival of hepatocellular carcinoma patients, the use of this grade in perihilar cholangiocarcinoma seems to be limited in patients with obstructive jaundice because this parameter contains total bilirubin. Very recently, the Kyoto group devised the ALPlat (albumin $\times$ platelets) criterion [3]. They calculated the probability of PHLF in the resection of hepatocellular carcinoma. This index does not include the bilirubin level but seems to be highly dependent on platelet count instead. Since the platelet count is seldom affected in livers with cholangiocarcinoma, it is still unclear whether this index appropriately predicts the PHLF in perihilar cholangiocarcinoma patients.

\section{Incorporation of Background Liver Function to FLR\%}

The evaluation of FLR function according to FLR\% and the hepatic functional reserve based on the abovementioned tests are usually discussed independently. However, in Japan, there has long been an attempt to integrate these two assessments using the FLR\% and the ICG clearance test.

\section{Future Remnant $K_{I C G}$}

The concept of future remnant (rem) $\mathrm{K}_{\mathrm{ICG}}$ began in 1980 with the study of Takasaki et al. [21]. In a canine model of liver resection by various volumes, they proved that $\mathrm{K}_{\mathrm{ICG}}$ was linearly correlated with the liver volume. The beauty of this study is that they used $\mathrm{K}_{\mathrm{ICG}}$, not $\mathrm{ICGR}_{15}$, even though these 2 values theoretically refer to the same thing. By using $\mathrm{K}_{\mathrm{ICG}}$, the correlation with liver volume is expressed as a linear correlation, and thus the liver function can be intuitively grasped as an amount. When using $\mathrm{ICGR}_{15}$, the correlation with liver volume is logarithmic, thus hindering an intuitive understanding of the liver function.

Twenty years ago, we reported that an estimated remnant liver $\mathrm{K}_{\mathrm{ICG}}$ (ER-K $\mathrm{K}_{\mathrm{ICG}}$ ), now often referred to as rem $\mathrm{K}_{\mathrm{ICG}}$, of $<0.03$ predicted patient mortality after hepatectomy, predominantly due to PHLF [22]. The value of rem $\mathrm{K}_{\mathrm{ICG}}$ is simply calculated with the formula: rem $\mathrm{K}_{\mathrm{ICG}}=\mathrm{K}_{\mathrm{ICG}} \times \mathrm{FLR} \%$. It represents the amount of $\mathrm{K}_{\mathrm{ICG}}$ allocated to the FLR. This relationship can be derived due to the linear correlation between $\mathrm{K}_{\mathrm{ICG}}$ and liver volume. At that time, it was difficult to calculate FLR\% from CT images. However, the development of computerized volumetry has enabled the precise calculation of FLR\% to be conducted in every hospital. Nagino et al. [23] and Yokoyama et al. [24] investigated the value of rem $\mathrm{K}_{\mathrm{ICG}}$ for predicting mortality and morbidity in extended hepatectomy for biliary cancer after percutaneous transhepatic portal vein embolization (PTPE) and derived a useful cutoff value of 0.05 . This cutoff value has since become the gold standard for assessing the tolerability for liver resection in Japan, making the use of $\mathrm{K}_{\mathrm{ICG}}$ more popular than ICGR $_{15}$ among hepatobiliary surgeons in Japan.

\section{Predicted LiMAx}

Predicted LiMAx is calculated by multiplying the preoperative LiMAx by FLR\%, as in rem $\mathrm{K}_{\text {ICG. Stockmann et }}$ al. [15] reported that the predicted LiMAx linearly correlated with measured LiMAx on postoperative day (POD) $1(r=0.85)$. On the other hand, optimal cutoff values of measured LiMAx on POD 1 were $85 \mu \mathrm{g} / \mathrm{kg} / \mathrm{h}$ for liver failure and $74 \mu \mathrm{g} / \mathrm{kg} / \mathrm{h}$ for patient death. The area under the receiver-operating characteristics curve (AUROC) for the prediction of liver failure and patient death
Yamamoto 
by the LiMAx test on POD 1 was 0.99 for both. This implies that predicted LiMAx $>85 \mu \mathrm{g} / \mathrm{kg} / \mathrm{h}$ would be a good predictor to prevent PHLF.

\section{Evaluation of Regional Heterogeneity of Liver Function}

Optimization techniques of FLR function such as portal vein embolization (PVE) [25], portal vein ligation (PVL) in two-stage hepatectomy [26], and associating liver partition and PVL for staged hepatectomy (ALPPS) [27] created a new situation with regional heterogeneity of liver function, where conventional CT volumetry cannot exert the ability to appropriately divide the liver function measured as a whole, such as $\mathrm{K}_{\mathrm{ICG}}$ and LiMAx, into the FLR part and the resection part. Nuclear imaging technology is expected to offer a solution to this issue. Using 3-dimensional single-photon emission (SPECT)-CT, detailed assessment of liver function corresponding to the liver segments becomes possible.

\section{${ }^{99 m}$ Tc-Mebrofenin Hepatobiliary SPECT-CT \\ Scintigraphy}

The details of this technology are described very precisely by de Graaf et al. [28]. Briefly, the technique enables us to calculate the functional FLR\% as a percentage of radioactivity counts within the FLR divided by the counts within the entire liver. They described a discrepancy of $>$ $10 \%$ between functional FLR\% and anatomical FLR\% in 9 of 36 patients, 7 of whom had a compromised liver. This suggests that this method delineates the functional heterogeneity of the background liver. In addition, to evaluate not only the distributional proportion of the function but also the actual regional function, they calculated the predictive liver function of FLR from the viewpoint of the ${ }_{99 \mathrm{~m}} \mathrm{Tc}$-mebrofenin uptake rate, by multiplying functional FLR\% by the total liver ${ }^{99 \mathrm{~m}} \mathrm{Tc}$-mebrofenin uptake rate measured during the dynamic hepatobiliary scintigraphy. They demonstrated that this value accurately predicted the actual liver function after liver resection. As a cutoff for predicting PHLF in patients with cholangiocarcinoma, Olthof et al. [29] reported that $8.5 \% / \mathrm{min}$ is adequate, where the ${ }^{99 \mathrm{~m}} \mathrm{Tc}$-mebrofenin uptake rate by the entire liver in a normal individual is $12.87 \pm 0.52 \% / \mathrm{min}$ [30].

There are, however, several drawbacks. Radioactivity counts in the bile system should be manually removed for an accurate calculation in some patients who have a fast hepatic uptake, because biliary excretion is already visible during the SPECT phase. The complexity of calculation of the uptake rate is also a matter from the perspective of versatility. It requires 3 time-activity curves: from the blood pool region of interest (ROI), liver ROI, and the entire field of view [31]. Last but not least, similar to the
ICG clearance test, ${ }^{99 \mathrm{~m}} \mathrm{Tc}$-mebrofenin uptake rate underestimates liver function when the serum bilirubin concentration is high $(50 \mu \mathrm{mol} / \mathrm{L}[3 \mathrm{mg} / \mathrm{dL}])$ because the transport of mebrofenin is also OATP-dependent [29].

\section{${ }^{99 m} T c-G S A$ SPECT-CT Scintigraphy}

Similar to ${ }^{99 \mathrm{~m}} \mathrm{Tc}$-mebrofenin hepatobiliary scintigraphy, SPECT images are also used for ${ }^{99 \mathrm{~m}} \mathrm{Tc}$-GSA scintigraphy. However, the evolution of its use was somewhat different from that for ${ }^{99 \mathrm{~m}} \mathrm{Tc}$-mebrofenin scintigraphy. The actual use of functional FLR\% from the viewpoint of ${ }^{99 \mathrm{~m} T c-G S A}$ uptake has been less active, probably because the simultaneously obtained information about liver function from parameters that are usually employed (LHL15 and HH15) were categorical rather than quantitative. However, due to the increasing availability of image analyzers on workstations in every hospital, the fusion technique with 3-dimensional vascular images obtained from contrast-enhanced CT scanning is now in the limelight (Fig. 1). The worth of adjusting the anatomical FLR\% with the distribution of ${ }^{99 \mathrm{~m}} \mathrm{Tc}$-GSA uptake is often discussed after PVE. It has been reported that functional FLR\% is higher than anatomical FLR\%, in the range of $5.9-13 \%$ [32-34].

One advantage of ${ }^{99 \mathrm{~m}} \mathrm{Tc}-\mathrm{GSA}$ scintigraphy over ${ }^{99 \mathrm{~m}} \mathrm{Tc}$ mebrofenin hepatobiliary scintigraphy is that the uptake of ${ }^{99} \mathrm{~m} \mathrm{Tc}-\mathrm{GSA}$ does not show early excretion to the bile system because it is a receptor-mediated scintigraphy. Therefore, there is no need to be concerned with the radioactivity from the bile system. Simple overlay of SPECT information through Digital Imaging and COmmunications in Medicine (DICOM) data on the 3-dimensional vascular image of the CT scan enables the calculation of the distribution difference from segment to segment. Another advantage is that the uptake of ${ }^{99 \mathrm{~m}} \mathrm{Tc}-\mathrm{GSA}$ is not affected by hyperbilirubinemia [35]. The drawback of this method is that ${ }^{99 \mathrm{~m}} \mathrm{Tc}-\mathrm{GSA}$ is not available for clinical use in Europe and the USA [28].

Because, unlike ${ }^{99 \mathrm{~m}} \mathrm{Tc}$-mebrofenin uptake rate, LHL15 and $\mathrm{HH} 15$ are qualitative, attempts have been made to use $\mathrm{K}_{\mathrm{ICG}}$ as the whole liver function to be proportionally divided according to the distribution of ${ }^{99} \mathrm{~m} \mathrm{Tc}-\mathrm{GSA}$ in calculating the fractional liver function [36]. However, it has not been yet clearly determined whether a rem $\mathrm{K}_{\mathrm{ICG}}$ $>0.05$ calculated by this method predicts PHLF more accurately than the conventional rem $\mathrm{K}_{\mathrm{ICG}}>0.05$. Similarly, because the liver uptake of ${ }^{99 \mathrm{~m}} \mathrm{Tc}-\mathrm{GSA}$ is mechanistically different from that of ${ }^{99 \mathrm{~m}} \mathrm{Tc}$-mebrofenin, it is not yet clear which test is more suitable with special reference to the prediction of PHLF. We await the results of more research.

Searches conducted in PubMed for the keywords, "GSA, liver, failure, assessment," or "mebrofenin, liver, failure, assessment," retrieved 20 related papers for the 


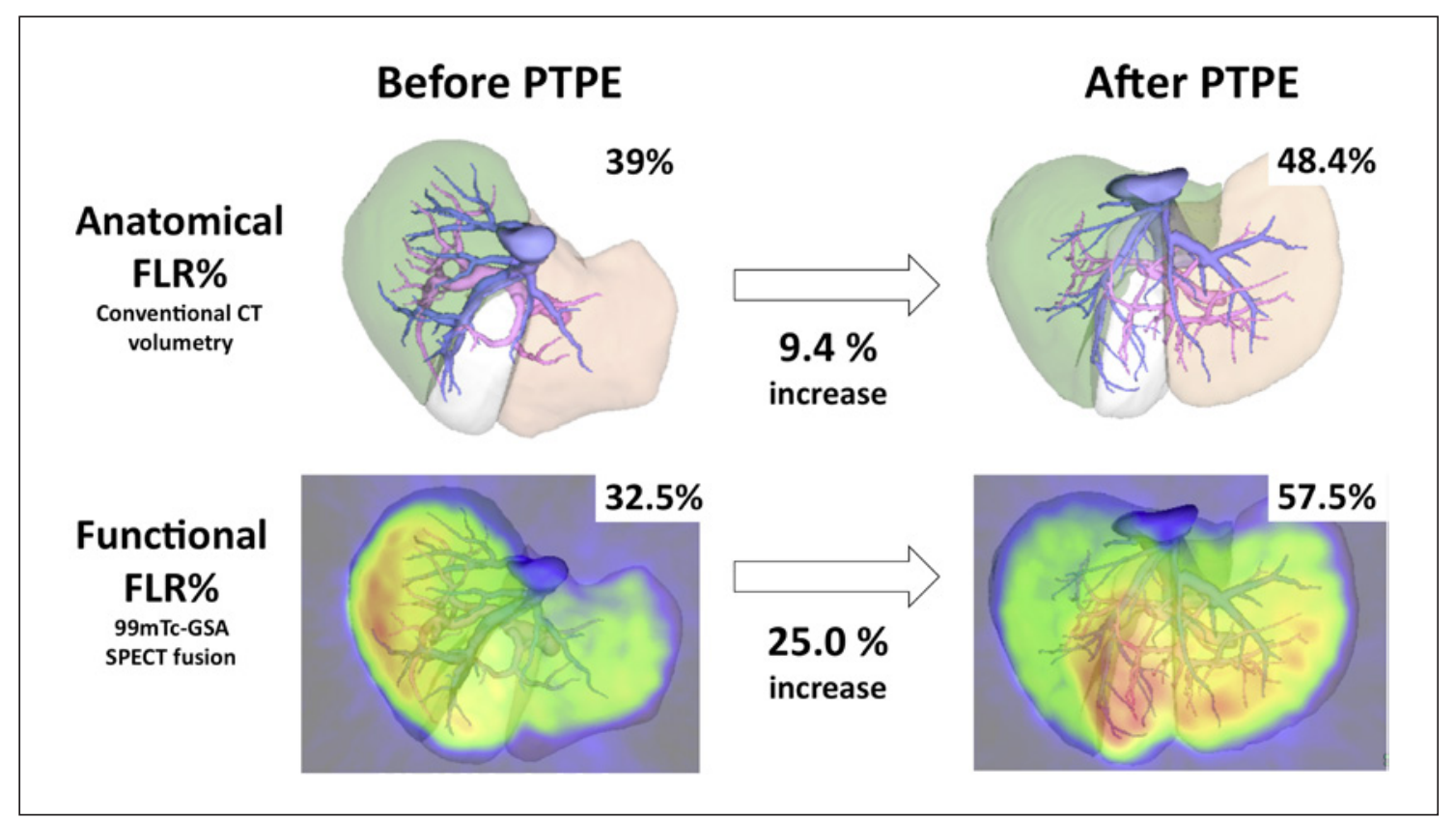

Fig. 1. Representative picture of fusion image of 3-dimensional vascular image obtained from contrast-enhanced CT scanning and ${ }^{99 m}$ Tc-GSA SPECT scintigraphy by SYNAPSE VINCENT ${ }^{\circledR}$. FLR\% (left liver) before and after PTPE is indicated. The anatomical increase of the left liver volume was 9.4\%, while functional increase was $25.0 \%$.

former terms and 23 for the latter terms. Interestingly, in the former, the papers found were published by a variety of institutions, but $43 \%$ of papers in the latter were from Amsterdam Medical Center. This may reflect that assessment with ${ }^{99 \mathrm{~m}} \mathrm{Tc}$-GSA scintigraphy is more widely spread, but that assessment with ${ }^{99 \mathrm{~m}} \mathrm{Tc}$-mebrofenin scintigraphy is still confined to special centers. The simplicity of data processing may be involved in this difference.

\section{Gd-EOB-DTPA-Enhanced MRI}

Gadolinium ethoxybenzyl dimeglumine (Gd-EOBDTPA) is a liver-specific MRI contrast agent. Gd-EOBDTPA distributes into the vascular and extravascular spaces during the arterial, portal, venous, and late dynamic phases, and progressively into the hepatocytes and bile ducts during the hepatobiliary phase. It is thus widely used to precisely diagnose the hepatic lesions before hepatectomy. Using the characteristic that the hepatocyte uptake of Gd-EOB-DTPA mainly occurs via the organic anion transporter polypeptides OATP1B1 and B3, trials to assess the FLR function including regional heterogeneity have been made. Geisel et al. [37] reported that lobar volume, kinetic growth rate, relative enhancement, and hepatocellular uptake index were able to be evaluated from routine Gd-EOB-DTPA-enhanced MRI study, and the last 2 of these parameters could replace the ICG test. Although there might be a limitation of use under hyperbilirubinemia, given the uptake mechanism of Gd-EOBDTPA, future development is awaited because the addi- tional medical expense is considered unnecessary for functional assessment only.

\section{Evaluation of Regional Heterogeneity Due to Venous}

Congestion Posthepatectomy

In extended hepatectomy that deprives the main hepatic veins which run the border of liver division, the influence of venous congestion posthepatectomy should be taken into account when estimating liver function. This impact has been actively discussed in the case of partial liver transplantation. When the area of congestion is significantly large, reconstruction of the venous drainage route will be considered, if possible. In cases where immediate recovery from congestion is not expected, it is proposed that the functional FLR\% be calculated, assuming that the functional volume of the congestive segment will be half of that volume. The background to this concept is from a clinical study in which the uptake of ICG dye in the veno-occlusive regions was about $40 \%$ of the non-veno-occlusive regions [38].

\section{Role of Biliary Drainage in Perihilar Cholangiocarcinoma}

The role of biliary drainage in bile duct cancer has long been under debate. According to Randi et al. [39], agestandardized incidence rates per 100,000 population of extrahepatic bile duct cancer is 3.3 times higher in Japan 
Fig. 2. Stent placement for biliary drainage. A Placement of two 7-Fr ERBD plastic stents on the resection side and a 6-Fr ENBD on the FLR side in a patient before right hepatectomy. Closed arrows indicate 7-Fr ERBD plastic stents placed in B8 and B6 branches of the right hepatic duct. Open arrow indicates a 6-Fr ENBD tube placed in the B2 branch of the left hepatic duct. B Parallel placements of 6-mm EMS on both sides in a patient before right hepatectomy. Closed arrow indicates the bifurcation of anterior and posterior branches of the right hepatic duct. Open arrow indicates the bifurcation of the right and left hepatic ducts.
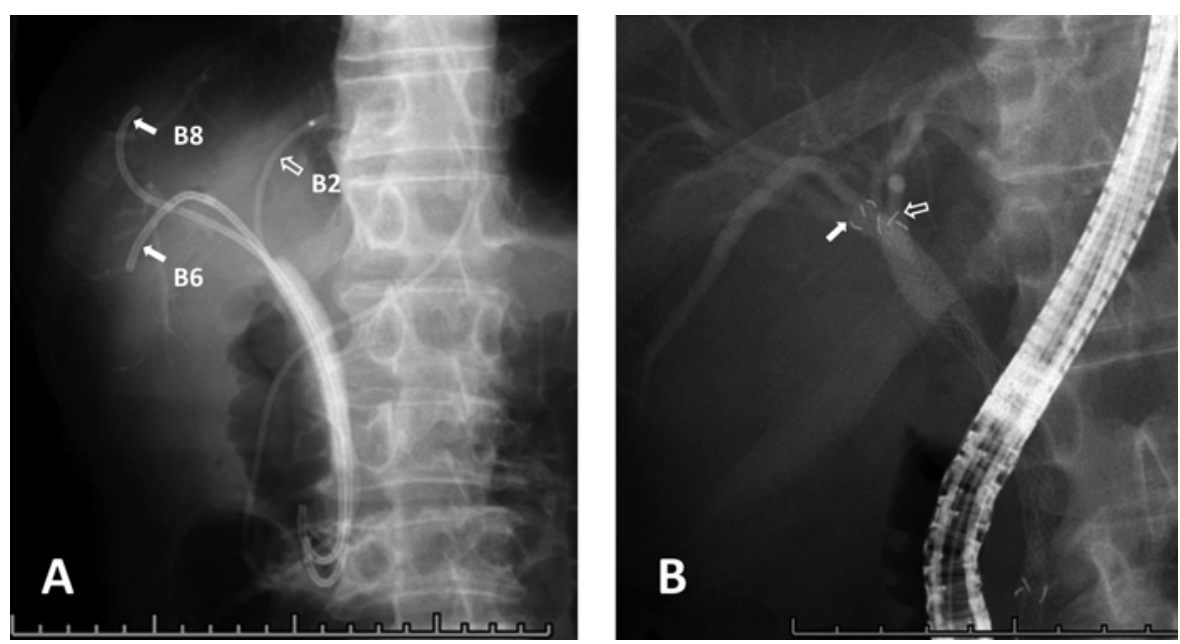

than in Germany (2.3 vs. 0.7). In Japan, precise diagnosis of tumor extent, especially the horizontal (axial) direction, is considered to be important to increase the resection rate. For this purpose, direct cholangiography has been aggressively performed, formerly percutaneous transhepatic biliary cholangiography PTCD) [40], and recently endoscopic retrograde cholangiography (ERCP), intraductal ultrasonography (IDUS), and peroral cholangioscopy (POCS) [41]. With this background, biliary drainage had been routinely performed simultaneously. Another reason that Japanese surgeons believe in the importance of preoperative biliary drainage is based on an early study by Koyama et al. [42]. They experimentally and clinically demonstrated that mitochondrial respiratory function deteriorates severely with the prolongation of biliary obstruction but recovers after relief of the obstruction. In addition, since the ICG clearance test is done routinely to evaluate the FLR function in Japan, surgery is performed after the serum bilirubin level has decreased to $<3 \mathrm{mg} / \mathrm{dL}$ as a logical consequence of biliary drainage.

In Western countries, several randomized control studies have been performed. These studies did not show differences in postoperative morality between the drainage group and the nondrainage group. On the contrary, the increase of complications during PTCD, septicemia and tract seeding of tumor cells emerged as adverse effects of PTCD [43]. On this clinical basis, considerable numbers of Western surgeons are still discouraged from performing preoperative biliary drainage. However, the nonuse of biliary drainage might also be associated with the policy of diagnostic workup of tumor extent as well. In Western countries, there is a tendency for diagnosis to rely only on MRI study/magnetic resonance cholangiopancreatography (MRCP) from the viewpoint of noninvasiveness [44]. Unlike direct cholangiography, biliary drainage to prevent infection after diagnostic workup is not necessary.

Evaluation Before Major Hepatic

Resection
Since the background of obstructive jaundice differed from study to study, it is still difficult to conclude this debate. Nevertheless, Iacono et al. [43] recommend biliary drainage in the majority of cases of proximal obstruction like perihilar cholangiocarcinoma, especially in patients whose FLR function is not sufficient and where PVE is necessary to optimize the function. It is also true that the number of institutions is increasing where the surgery is performed after enough biliary drainage, referring to good surgical results in Japan [45].

Concerning the method of biliary drainage, PTCD is now less frequently used so as to prevent drainage-related complications. Either endoscopic nasobiliary drainage (ENBD), endoscopic retrograde biliary drainage using plastic stent (ERBD), or in combination when bilateral drainage is necessary, are optional according to the anticipated period for drainage and the presence of infection (Fig. 2a). To prevent post-ENBD cholangitis, placement of the tube without endoscopic sphincterotomy (EST) is recommended [46]. In patients who need PVE, ERBD is more comfortable because of the long waiting period. However, ENBD is preferred for patients who have repeat cholangitis. Expandable metallic stent (EMS) placement is less useful for preoperative biliary drainage for proximal bile duct obstruction because it may hamper obtaining an appropriate resection margin and reconstruction of the biliary tract. However, it can be useful when the placement does not interfere with surgery and, at the same time, there is concern about stent occlusion due to the fairly long waiting time before surgery (Fig. 2b). Unilateral drainage of the FLR is currently recommended to prompt hypertrophy of the FRL induced by PVE and to guarantee good liver function before major hepatectomy, as long as there is no cholangitis on the side of the resection [47]. In cases of total external drainage, oral (via tube if necessary) reinfusion of the bile is strongly recommended to increase the regenerative power of the liver and maintain intestinal function [48]. 


\section{Conclusion}

Appropriate selection of an assessment method is of importance for predicting the FLR function according to the preoperative condition of the liver. The role of biliary drainage in patients with obstructive jaundice is still under debate. However, preoperative drainage in patients with perihilar cholangiocarcinoma is gaining support, along with the increasing safety and success rate, especially in patients who need optimization of their liver function before hepatectomy.

\section{Statement of Ethics}

Ethical considerations were not applicable to this review article. All images were obtained with informed consent from the patients and anonymized.

\section{Conflict of Interest Statement}

The authors have no conflicts of interest to declare.

\section{Funding Sources}

There was no funding.

\section{Author Contributions}

Y.Y. performed the literature searches and wrote the manuscript.

\section{References}

1 Franken LC, Schreuder AM, Roos E, van Dieren S, Busch OR, Besselink MG, et al. Morbidity and mortality after major liver resection in patients with perihilar cholangiocarcinoma: A systematic review and meta-analysis. Surgery. 2019 May;165(5):918-28.

2 Kenjo A, Miyata H, Gotoh M, Kitagawa Y, Shimada $\mathrm{M}$, Baba $\mathrm{H}$, et al. Risk stratification of 7,732 hepatectomy cases in 2011 from the National Clinical Database for Japan. J Am Coll Surg. 2014 Mar;218(3):412-22.

3 Yamamoto G, Taura K, Ikai I, Fujikawa T, Nishitai R, Kaihara S, et al. ALPlat criterion for the resection of hepatocellular carcinoma based on a predictive model of posthepatectomy liver failure. Surgery. 2020 Feb;167(2): 410-6.

4 Belghiti J, Hiramatsu K, Benoist S, Massault P, Sauvanet A, Farges O. Seven hundred fortyseven hepatectomies in the 1990s: an update to evaluate the actual risk of liver resection. J Am Coll Surg. 2000 Jul;191(1):38-46.

5 Shirabe K, Shimada M, Gion T, Hasegawa H, Takenaka K, Utsunomiya T, et al. Postoperative liver failure after major hepatic resection for hepatocellular carcinoma in the modern era with special reference to remnant liver volume. J Am Coll Surg. 1999 Mar;188(3): 304-9.

6 Vauthey JN, Abdalla EK, Doherty DA, Gertsch P, Fenstermacher MJ, Loyer EM, et al. Body surface area and body weight predict total liver volume in Western adults. Liver Transpl. 2002 Mar;8(3):233-40.

7 Beppu T, Hayashi H, Okabe H, Masuda T, Mima K, Otao R, et al. Liver functional volumetry for portal vein embolization using a newly developed 99mTc-galactosyl human serum albumin scintigraphy SPECT-computed tomography fusion system. J Gastroenterol. 2011 Jul;46(7):938-43.

8 Ohshima S. Volume analyzer SYNAPSE VINCENT for liver analysis. J Hepatobiliary Pancreat Sci. 2014 Apr;21(4):235-8.
9 Saito S, Yamanaka J, Miura K, Nakao N, Nagao T, Sugimoto T, et al. A novel 3D hepatectomy simulation based on liver circulation: application to liver resection and transplantation. Hepatology. 2005 Jun;41(6):1297-304.

10 Radtke A, Sotiropoulos GC, Nadalin S, Molmenti EP, Schroeder T, Lang H, et al. Preoperative volume prediction in adult living donor liver transplantation: how much can we rely on it? Am J Transplant. 2007 Mar;7(3): 672-9.

11 Imamura H, Seyama Y, Kokudo N, Maema A, Sugawara Y, Sano K, et al. One thousand fiftysix hepatectomies without mortality in 8 years. Arch Surg. 2003 Nov;138(11):1198206.

12 Ishizawa T, Masuda K, Urano Y, Kawaguchi Y, Satou S, Kaneko J, et al. Mechanistic background and clinical applications of indocyanine green fluorescence imaging of hepatocellular carcinoma. Ann Surg Oncol. 2014 Feb; 21(2):440-8

13 Oellerich M, Raude E, Burdelski M, Schulz M, Schmidt FW, Ringe B, et al. Monoethylglycinexylidide formation kinetics: a novel approach to assessment of liver function. J Clin Chem Clin Biochem. 1987 Dec;25(12):84553.

14 Ercolani G, Grazi GL, Callivà R, Pierangeli F, Cescon M, Cavallari A, et al. The lidocaine (MEGX) test as an index of hepatic function: its clinical usefulness in liver surgery. Surgery. 2000 Apr;127(4):464-71.

15 Stockmann M, Lock JF, Riecke B, Heyne K, Martus P, Fricke M, et al. Prediction of postoperative outcome after hepatectomy with a new bedside test for maximal liver function capacity. Ann Surg. 2009 Jul;250(1):119-25.

16 Makridis G, Oldhafer KJ. First intraoperative measurement of liver functional capacity during liver surgery using the $13 \mathrm{C}$-methacetin breath test: early results of a pilot study. J Hepatobiliary Pancreat Sci. 2020 May;27(5): 280-1.
17 Sawamura T, Nakada H, Hazama H, Shiozaki Y, Sameshima Y, Tashiro Y. Hyperasialoglycoproteinemia in patients with chronic liver diseases and/or liver cell carcinoma. Asialoglycoprotein receptor in cirrhosis and liver cell carcinoma. Gastroenterology. $1984 \mathrm{Dec}$; 87(6):1217-21.

18 Kudo M, Vera DR, Stadalnik RC, Trudeau WL, Ikekubo K, Todo A. In vivo estimates of hepatic binding protein concentration: correlation with classical indicators of hepatic functional reserve. Am J Gastroenterol. 1990 Sep;85(9):1142-8.

19 Koizumi K, Uchiyama G, Arai T, Ainoda T, Yoda Y. A new liver functional study using Tc-99m DTPA-galactosyl human serum albumin: evaluation of the validity of several functional parameters. Ann Nucl Med. 1992 May;6(2):83-7.

20 Johnson PJ, Berhane S, Kagebayashi C, Satomura S, Teng M, Reeves HL, et al. Assessment of liver function in patients with hepatocellular carcinoma: a new evidence-based approach-the ALBI grade. J Clin Oncol. 2015 Feb;33(6):550-8.

21 Takasaki T, Kobayashi S, Suzuki S, Muto H, Marada M, Yamana Y, et al. Predetermining postoperative hepatic function for hepatectomies. Int Surg. 1980 Jul-Aug;65(4):309-13.

22 Yamamoto Y, Ikai I, Kume M, Sakai Y, Yamauchi A, Shinohara H, et al. New simple technique for hepatic parenchymal resection using a Cavitron Ultrasonic Surgical Aspirator and bipolar cautery equipped with a channel for water dripping. World J Surg. 1999 Oct; 23(10):1032-7.

23 Nagino M, Kamiya J, Nishio H, Ebata T, Arai T, Nimura Y. Two hundred forty consecutive portal vein embolizations before extended hepatectomy for biliary cancer: surgical outcome and long-term follow-up. Ann Surg. 2006 Mar;243(3):364-72. 
24 Yokoyama Y, Nishio H, Ebata T, Igami T, Sugawara G, Nagino M. Value of indocyanine green clearance of the future liver remnant in predicting outcome after resection for biliary cancer. Br J Surg. 2010 Aug;97(8):1260-8.

25 Shinkawa H, Takemura S, Tanaka S, Kubo S Portal Vein Embolization: History and Current Indications. Visc Med. 2017 Dec;33(6): 414-7.

26 Jaeck D, Oussoultzoglou E, Rosso E, Greget M, Weber JC, Bachellier P. A two-stage hepatectomy procedure combined with portal vein embolization to achieve curative resection for initially unresectable multiple and bilobar colorectal liver metastases. Ann Surg. 2004 Dec;240(6):1037-49.

27 Schlitt HJ, Hackl C, Lang SA. 'In-Situ Split' Liver Resection/ALPPS - Historical Development and Current Practice. Visc Med. 2017 Dec;33(6):408-12.

28 de Graaf W, van Lienden KP, van Gulik TM, Bennink RJ. (99m)Tc-mebrofenin hepatobiliary scintigraphy with SPECT for the assessment of hepatic function and liver functional volume before partial hepatectomy. J Nucl Med. 2010 Feb;51(2):229-36.

29 Olthof PB, Coelen RJ, Bennink RJ, Heger M, Lam MF, Besselink MG, et al. 99mTc-mebrofenin hepatobiliary scintigraphy predicts liver failure following major liver resection for perihilar cholangiocarcinoma. HPB $(\mathrm{Ox}-$ ford). 2017 Oct;19(10):850-8.

30 Erdogan D, Heijnen BH, Bennink RJ, Kok M, Dinant S, Straatsburg IH, et al. Preoperative assessment of liver function: a comparison of 99mTc-Mebrofenin scintigraphy with indocyanine green clearance test. Liver Int. 2004 Apr;24(2):117-23.

31 Ekman M, Fjälling M, Friman S, Carlson S, Volkmann R. Liver uptake function measured by IODIDA clearance rate in liver transplant patients and healthy volunteers. Nucl Med Commun. 1996 Mar;17(3):235-42.

32 Hayashi H, Beppu T, Okabe H, Kuroki H, Nakagawa S, Imai K, et al. Functional assessment versus conventional volumetric assessment in the prediction of operative outcomes after major hepatectomy. Surgery. 2015 Jan;157(1): 20-6.
33 Tsuruga Y, Kamiyama T, Kamachi H, Shimada S, Wakayama K, Orimo T, et al. Significance of functional hepatic resection rate calculated using 3D CT/(99m)Tc-galactosyl human serum albumin single-photon emission computed tomography fusion imaging. World J Gastroenterol. 2016 May;22(17): 4373-9.

34 Akaki S, Okumura Y, Sasai N, Sato S, Tsunoda M, Kuroda M, et al. Hepatectomy simulation discrepancy between radionuclide receptor imaging and CT volumetry: influence of decreased unilateral portal venous flow. Ann Nucl Med. 2003 Feb;17(1):23-9.

35 Nakano H, Kumada K, Takekuma Y, Hasebe S, Yoshizawa Y, Yamaguchi M, et al. Perioperative hepatic functional risk assessed with technetium-99m diethylenetriamine pentaacetic acid-galactosyl human serum albumin liver scintigraphy in patients undergoing pancreaticoduodenectomy complicated by obstructive jaundice. Int J Pancreatol. 1999 Feb; 25(1):3-9.

36 Kaihara S, Iwamoto S, Uryuhara K, Hosotani R. Preoperative remnant liver function assessment in major hepatectomy after portal vein embolization using 99mTc-GSA scintigraphy / 3D-CT fused image. HPB (Oxford). 2017;19 $\mathrm{S} 1: \mathrm{S} 102$.

37 Geisel D, Raabe P, Lüdemann L, Malinowski M, Stockmann M, Seehofer D, et al. Gd-EOBDTPA-enhanced MRI for monitoring future liver remnant function after portal vein embolization and extended hemihepatectomy: A prospective trial. Eur Radiol. 2017 Jul;27(7): 3080-7.

38 Kawaguchi Y, Ishizawa T, Miyata Y, Yamashita S, Masuda K, Satou S, et al. Portal uptake function in veno-occlusive regions evaluated by real-time fluorescent imaging using indocyanine green. J Hepatol. 2013 Feb;58(2): 247-53.

39 Randi G, Malvezzi M, Levi F, Ferlay J, Negri E, Franceschi S, et al. Epidemiology of biliary tract cancers: an update. Ann Oncol. 2009 Jan; 20(1):146-59.
40 Nagino M, Nimura Y, Kamiya J, Kondo S, Kanai M, Miyachi M, et al. Preoperative management of hilar cholangiocarcinoma. J Hep Bil Pancr Surg. 1995;2(3):215-23.

41 Miyazaki M, Yoshitomi H, Miyakawa S, Uesaka K, Unno M, Endo I, et al. Clinical practice guidelines for the management of biliary tract cancers 2015: the 2nd English edition. J Hepatobiliary Pancreat Sci. 2015 Apr;22(4): 249-73.

42 Koyama K, Takagi Y, Ito K, Sato T. Experimental and clinical studies on the effect of biliary drainage in obstructive jaundice. Am J Surg. 1981 Aug;142(2):293-9.

43 Iacono C, Ruzzenente A, Campagnaro T, Bortolasi L, Valdegamberi A, Guglielmi A. Role of preoperative biliary drainage in jaundiced patients who are candidates for pancreatoduodenectomy or hepatic resection: highlights and drawbacks. Ann Surg. 2013 Feb;257(2): 191-204.

44 Khan SA, Davidson BR, Goldin RD, Heaton N, Karani J, Pereira SP, et al.; British Society of Gastroenterology. Guidelines for the diagnosis and treatment of cholangiocarcinoma: an update. Gut. 2012 Dec;61(12):1657-69.

45 Belghiti J, Ogata S. Preoperative optimization of the liver for resection in patients with hilar cholangiocarcinoma. HPB (Oxford). 2005; 7(4):252-3.

46 Kawashima H, Itoh A, Ohno E, Itoh Y, Ebata T, Nagino M, et al. Preoperative endoscopic nasobiliary drainage in 164 consecutive patients with suspected perihilar cholangiocarcinoma: a retrospective study of efficacy and risk factors related to complications. Ann Surg. 2013 Jan;257(1):121-7.

47 Ishizawa T, Hasegawa K, Sano K, Imamura H, Kokudo N, Makuuchi M. Selective versus total biliary drainage for obstructive jaundice caused by a hepatobiliary malignancy. Am J Surg. 2007 Feb;193(2):149-54.

48 Kamiya S, Nagino M, Kanazawa H, Komatsu S, Mayumi T, Takagi K, et al. The value of bile replacement during external biliary drainage: an analysis of intestinal permeability, integrity, and microflora. Ann Surg. 2004 Apr; 239(4):510-7. 